\title{
How to Nurture Ground for Arts-Based Co-Creative Practice in an Invited Space: Reflections on a Community in North Netherlands
}

Scott Davis, Yanthe van Nek, and Lummina G. Horlings

\section{Introduction}

Place-based cultural projects are increasingly considered by governments as capable of fostering a greater 'sense of local identity' and strengthening social cohesiveness within local communities. The launch of such a project is often initiated by an external authority, such as a government, opening up and overseeing an 'invited space'. Creative practitioners and community members are then invited to create an artistic or creative output of public value as a cultural expression of the community. Situations in which the practitioner is assigned by the governmental authority can, however, be challenging from a power relations perspective. A lack of local agency over the project design and its direction can potentially result in scepticism and dis-trust of participants and, consequently, low levels of community engagement.

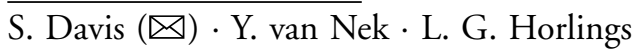
University of Groningen, Groningen, The Netherlands e-mail: s.davis@rug.nl 
In western-European countries there has been a generational shift in public governance from community engagement and empowerment principles as generalized rhetoric, to a situation whereby concepts such as participatory governance and bottom-up approaches can routinely be found embedded within public policy strategies (de Andrade, 2016; MacKinnon, 2002). Policies that aspire for more participative and engaged communities can be considered as place-based; working within local contexts to build on the characteristics and culture of a place and community. This is grounded in an appreciation that much of the knowledge necessary for local development is not held by public and private institutions but embodied by people on the ground (Barca, 2009). The rationale behind governments commissioning place-based cultural projects in order to shape community futures, resides in the understanding that 'bottom-up' practical projects are more effective in influencing the attitudes and behaviours of communities than the traditional delivery of 'top-down' rational, ideological doctrines (Svensson, 2012). The 'culture' of a place is therefore increasingly viewed by governments as a valuable asset for sustainable development, to strengthen societal resilience and improve people-centred social outcomes (Duxbury \& Jeanotte, 2007; Dessein et al., 2015; UCLC, 2008; Hawkes, 2001).

As a conceptual term, culture has an array of definitions attributed to it, encompassing all the ways we make sense of our lives together, referred to as 'the social production of meaning' (Hawkes, 2001). Culture encapsulates all of our values, practices and interactions involving both human and non-human forms, including socio-technical systems and technologies (Williams, 1980). The term can therefore be applied to almost any social context. Some critics posit 'culture' as an overused term as they consider it much too broad to hold significance within sustainability discourse; it can mean anything from a network of meaning, to a way of life, to high culture and arts (Throsby, 2008).

In this chapter we narrow the focus specifically to place-based culture. Places contain a vast amount of human history that informs cultural norms; the historic perceptions people have of their places are often connected to their attitudes, policies and political/economic consequences that result from these perceptions (Shortridge, 2005). Williams (1980, p. 67) articulates how our landscapes can also be considered 
a part of our place-based culture: 'The environment around us-our plants, gardens, wildlife, living things should be considered as an important part of this "culture" as the idea of nature contains an extraordinary amount of human history'. The growing calls for place-based culture to be utilized as an asset for local sustainability planning, however, also enhance the threat of its mis-use. Place-based culture risks being utilized in an instrumentalist manner by those in authority to achieve their own pre-defined outcomes that fail to address, or are even in conflict with, local needs (see Van der Vaart, this book). Projects and initiatives that apply arts-based co-creative practice with communities are not immune from this charge and are in danger of being co-opted by managerialist governance approaches that can use such methods as cover to mask neo-liberal orthodoxies. This covert practice is described by MacKinnon (2002) as governing through community, operating as an instrumental governance strategy that functions to obscure existing power inequalities and therefore limits the potential for transformation and social change (Noorani et al., 2013).

In the Netherlands, but also in other countries (Grenni et al., 2020; Neal, 2015), we witness situations where community creative practitioners (i.e., those who utilize arts-based methods to engage with communities for social change) are commissioned by external authorities_commonly local or regional governments - to facilitate arts-based co-creative practice to provide a platform for local knowledge and values to be brought to the surface (Horlings, 2017). Community creative practitioners are often inspired by, or demonstrate a strong overlap with, participative action research (PAR) approaches. They work by applying their creative and facilitative skill sets to tap into the power of cultural activities (e.g., community music and theatre initiatives) that can provide opportunity for the construction of new forms of subjectivity and reach people on 'the affective' level, promoting their capacity to perceive new possibilities (Mouffe, 2013). This is based on the assumption that engagement through cultural projects can unlock communities' 'transformative potential and thus challenge dominant representations and ways of knowing, facilitate dialogue across ideological and epistemological boundaries and change hearts and minds through building intellectual and affective understanding' (Nunn, 2020, p. 4). 
One might expect such a process to be inherently inductive, grassroots or 'bottom-up', operating as it does at the community level. However, this is not always the case and cannot be assumed when local, cultural projects are assigned by an external state authority. In this chapter we argue that a characteristic of paternalism may be present and, if so, must be considered whenever a creative practitioner is invited to work on a local, place-based project. While we encourage the state sector to embrace local, place-based approaches, we also advocate for heightened awareness regarding how state commissioned projects may serve or prioritize external agendas — partially or fully divorced from community needs and therefore not fully reflective of the bottom-up, grassroots values one would expect from projects engaging with place-based culture. We therefore suggest those who are embarking on an arts-based co-creative journey to become aware of, and take steps to address the challenges of working in participative spaces that are opened up within such projects. In doing so they are encouraged to regularly reflect upon and take seriously such questions as: who is initiating the invitation, on whose authority, and what interests are motivating it.

The questions guiding this chapter are therefore: How can creative practitioners deal with the constraints of being invited into a participative space when first engaging with a community? How then to respond to the wishes of the community on their own terms, rather than respond to external interests? How can this inform those who are considering using arts-based co-creative practice to engage with communities in the future? The three questions posed are critically explored by viewing the case through the conceptual lens of 'invited spaces' (Gaventa, 2006) (see section 8.2 below).

This chapter is primarily an interpretative analysis of the case detailed by a researcher, the first author. The data for this chapter were derived from the researcher's personal observations of the creative practitioners' strategy in the field, and a series of open and semi-structured interviews with the second author, the creative practitioner Yanthe van Nek, who reflected on her time working in the village. The analysis is informed by the co-creative community engagement strategy that she undertook and documented in the described village. The third author, the book editor and an external reviewer provided valuable contributions to the chapter. 
The creative practitioner was invited by the provincial government to work with village residents in order to facilitate a cultural expression of the place-in essence 'art-making as a way of knowing' (Leavy, 2018 , p. 4). The local project was one part of a wider programme of government-funded cultural projects across the province of Groningen in the Netherlands; commissioned to strengthen cultural infrastructure and social connectedness of residents to their places. This was in light of the provincial government's decision to centralize existing municipalities into larger but fewer entities. The residents within this particular village were also in the midst of dealing with the impact of energy transition developments as a result of government policy decisions, most notably the approved construction of a windpark within their village and immediate landscape. Throughout the time frame of the study, the residents were experiencing significant transformations externally imposed upon them that affected their daily lives and their immediate environment. As a result of these policy decisions, a local village protest group was formed in opposition to the windpark site construction. The decision of the regional government to commission and invite the village residents to work with a creative practitioner on a place-based cultural project of their village therefore re-raised questions noted earlier-who is doing the inviting and what are the motivations that underlie the invitation to participate?

While the specifics of this case are unique and we do not claim full generalizability, we aim to draw lessons that can support those participating in projects operating under similar conditions. The case described in this chapter illustrates what Neal (2015) describes as 'art of invitation' principles in a community engagement strategy. We will argue that trust-building and fostering community agency are important in such a strategy, especially when working within a project under invited space conditions. Implementing an engagement strategy that addresses power imbalances and re-centres a project around community needs, can encourage project legacies that last beyond the timespan of a project and alleviate the criticism that practitioners and/or researchers parachute in and out of communities (Bastida et al., 2010).

The chapter continues as follows: the next section introduces the theoretical lens of invited spaces and the constraining consequences of an 
invitational space. We then explain the philosophy applied by the creative practitioner, Yanthe van Henk, addressing these constraints, and how her way of working reflects elements of participatory action research, notably the 'art of invitation' principles. The chapter then outlines the case and the research methodology. The results section describes and provides an analysis of how Yanthe engaged with the community in the initial stages of the project, nurturing the ground for creative art-based practice. The chapter closes with reflections on the findings and conclusions on the implications of the role of researchers and practitioners in externally commissioned place-based cultural projects.

\section{The Concept of Invited Spaces}

\section{Invited Spaces as a Situational Constraint}

In 2006, the political sociologist John Gaventa published a concept known as the power cube. The power cube is a conceptual framework designed to support the analysis of how communities interrelate with different levels, spaces and forms of power. This chapter focuses specifically on one component of the cube called the invited space.

Invited spaces are created where there is a request for community participation, involvement or consultation, usually from a particular governmental authority - typically a local, regional or national government (Gaventa, 2006). Spaces of this nature are designed as a governmental strategy with the view of strengthening the individual and collective agency of a population, by providing a participative opportunity for people to express their views, to potentially affect or influence future cultural, social and political discourses within their locality (Gaventa, 2006). The concept of an invited space helps us to understand the challenges that emerge for a creative practitioner when they are asked to facilitate a cultural process with a community by an external authority.

When a space is opened up by an authority and citizens are invited to participate, this can potentially present a channel where citizens can challenge dominant discourses, decisions, policies and relationships that affect their lives and interests (Gaventa, 2006). Within such an invited 
space however, as Gaventa critically explains, those in authority who govern the space also often shape the boundaries of these spaces of participation, what is possible within them, and which or what discourses and interests may enter the space. This results in restrictions of freedom for those participating, including how issues are framed and the limits over what can take place within these spaces (Gaventa, 2006). The notion of freedom within Gaventa's conceptual understanding of power is drawn from the work of Hayward, who defines freedom in a participative context as 'the capacity to participate effectively in shaping the social limits that define what is possible' (Hayward, 1998, p. 2). Upon this interpretation free participation can be seen as not only the right to participate within a given space, but also the right to define and shape that space (Gaventa, 2006). This is closely aligned to the degree of agency a community is permitted within the invited space.

Typically, invited spaces are set up in more formal deliberative processes (e.g., community consultations) where citizens are consulted about specific projects or decisions. We would argue that place-based cultural projects commissioned by governments to achieve certain desired social outcomes, can also be viewed through the lens of invited spaces. These projects run the risk of mis-using culture whereby 'sense of place' interventions are applied in an instrumental, predetermined manner within externally set boundaries; curtailing what can be deliberated and achieved within the space rather than the framing of the space being co-designed with the community.

Regardless of whether the invited space is shaped in a more traditional community consultation format or through participative place-based projects, within both examples there is a risk that an invited space is created as a form of top-down steering, sponsored by authorities. As Aiyar (2010) argues, these initiatives inevitably contain power asymmetries whereby the invited space is somewhat bound by the norms of the state. This means that the purpose, mandate and remit of such spaces are circumscribed by the agendas of the implementing agencies, framing the perspective of the issues that surface and the grounds on which these issues can be debated (Cornwall, 2002). Furthermore, the authority monitors and holds a power of veto over project activities; therefore, 
the final say from any expressed desire still resides with the authoritative power (Gaventa, 2009). It can be said that the notion of an invited space-in this case where a place-based cultural project was commissioned-cannot be considered bottom-up and autonomous; but rather top-down designed, resulting in the emergence of paternalist characteristics. The concept of invited spaces and the skewed power dynamics that result from this type of community engagement can therefore be considered as a key constraint for practitioners working with communities co-creatively under these conditions.

To address these power imbalances inherent within projects commissioned under 'invited space' conditions, PAR approaches have been developed in the last decades to support the democratization of community engagement. PAR approaches have demonstrated the potential to disrupt existing power orthodoxies, by building alternative power bases from the bottom up, creating alliances between those involved in the process, resulting in more horizontal relationships (Anderson, 2017).

\section{Participatory Action Research: An Overview}

PAR was developed as a critical response to traditional, positivistic research approaches whereby the role and positionality of the researcher was one of a passive observer (Oakley \& Marsden, 1985). Instead, PAR situates both the researcher and the community as active agents of the research process-conducting co-operative enquiry (Heron \& Reason, 2006) with the objective of enabling structured transformation, often with the social justice aim(s) of changing the living conditions of people in a specific place (Kelly \& van der Riet, 2001). PAR seeks to achieve this objective by integrating three basic principles: Participation (life in society and democracy), Action (engagement with experience and history), and Research (soundness in thought and the growth of knowledge) (Chevalier \& Buckles, 2013).

PAR approaches within communities have become increasingly popular as a social science research method (Wilson et al., 2017) due, in part, to the potential of PAR to democratize the research process and empower communities for social change (Chevalier \& Buckles, 
2013; Hacker, 2013). PAR promotes democratizing elements that focus on a researcher's responsibility to the participants (Datta et al., 2014) rather than the relationship existing as 'hierarchical, vertical, dominating, and [potentially] exploitative' (Kesby, 2005, p. 2051). In this vein, indigenous scholar Battiste (2008) suggests that the research should transfer power through the researcher's respect and accountability to the participants. The researcher should not only learn about the residents but also learn from them, exchanging experiences, understanding and empathizing with the value of their subjective experiences and ensuring active involvement and/or leadership roles in the conceptualization, design and implementation of the co-creative process.

This sphere of engagement created between a researcher and the community can be understood as a 'field of relationships built on mutual trust, and interests that, if not identical, converge around a certain set of activities where researchers' and participants' 'respective paths cross or commingle"' (Ingold, 2000, p. 145), highlighting the necessity for reciprocal engagement in co-creative practice to be effective. Co-creative practice within PAR can be defined as a joint or partnership-oriented creative approach between two or more parties, especially between an institution and constituents, towards achieving a desired outcome (van Westen \& van Dijk, 2015). These co-creative processes with communities often involve emotionally labour-intensive relationship building (Facer \& Enright, 2016), whereby researchers and practitioners are viscerally engaged in the 'messy realities' of other people's lives (Carter et al., 2013; Thomas-Hughes, 2018). While the term is sometimes used interchangeably with 'collaboration', co-creation is said to place a greater emphasis on process (van Westen \& van Dijk, 2015; see also Franklin, this book). This process can assist in the democratization and empowerment process of PAR by valuing local knowledge, brokering connections, building trust and facilitating the emergence of collaborative problem solving and community leadership (Metz et al., 2019). However, to reach the point where effective arts-based co-creative practice is possible, it is necessary to first implement an appropriate community engagement strategy that is sensitive to the local context and addresses the constraint of being externally invited to co-create with the community. In the next 
section we will describe how these conditions can be created via the 'art of invitation'.

\section{The Art of Invitation: Becoming a Voluntary Instrument of a Community}

The 'art of invitation' can be seen as a PAR inspired approach. The term has been coined by Ruth Ben Tovim, Lucy Neal and Anne Marie Culhane, all artists in their own right, but also all members of Encounters, an organization established in 2003. Encounters was born from a community project whereby co-founders Ruth Ben-Tovim and Trish O'Shea took over a disused shop in Sharrow, Sheffield (UK), to open a creative dialogue about their rapidly changing local neighbourhood:

We see ourselves as bridge builders and space holders for an exchange to happen between a civic institution and its participants - many of whom might never have experienced or participated in a more formal art context before. (Encounters A).

Encounters describes the art of invitation as follows: 'The Art of Invitation demonstrates how to engage different communities in becoming involved in creative projects; bringing people together to make social, cultural and ecological change happen' (Encounters B). We draw here mainly on the work of Lucy Neal (2015), whose book: Playing for time, making art as if the world mattered, provides a rich overview of art-based practices of a wide group of creative practitioners. It is a handbook with narratives on collaboration and co-creation with communities. A key assumption is that 'art is in service of lives', which enables holding one's gaze on the challenge of re-imagining the future (p. 14). Art-based engagement with communities can be considered as a place-based strategy, applied, for instance, in the transition town of Totnes, England (Hopkins, 2015), as a strategy of activism (Khan, 2015) and as a strategy to reclaim the (food) commons (Gordon-Fairleigh, 2015). Without making the claim to outline a formal methodology, key principles that outline conditions for effective community engagement for art-based activities have been described by Neal (2015) and are summarized and listed in Table 8.1. 
Table 8.1 Ten principles of 'the art of invitation'

\begin{tabular}{|c|c|}
\hline Principle & Description \\
\hline Intention & $\begin{array}{l}\text { The intention is to create conditions for change. } \\
\text { This can feel open-ended, with no precise } \\
\text { plan, but engaging in intent gives life to the } \\
\text { choices we make about change. Intentions } \\
\text { may have an impulse that is self-directed but } \\
\text { contain a generosity towards others within this }\end{array}$ \\
\hline Frame & $\begin{array}{l}\text { A boundary of structure within which the } \\
\text { freedom to play exists, creating the context or } \\
\text { narrative for people to explore. Too large a } \\
\text { frame can lack focus; too tight a one will not } \\
\text { be expandable or open to change. It is a lens } \\
\text { through which we can look at daily life anew. } \\
\text { The lens can be changed as the project } \\
\text { proceeds, opening choices up or closing them } \\
\text { down }\end{array}$ \\
\hline Work with community & $\begin{array}{l}\text { A practice of community fosters self-awareness, } \\
\text { empathy, vulnerability and realism to help us } \\
\text { evolve. Art-based practices can bring people } \\
\text { together that are not like-minded, and have } \\
\text { different backgrounds and experiences }\end{array}$ \\
\hline Facilitate & $\begin{array}{l}\text { Facil means easy. Facilitation involves getting } \\
\text { things to flow, overcoming obstacles such as } \\
\text { scepticism. Some aspects of facilitation can be } \\
\text { predicted and organized, but much will need } \\
\text { improvizing and intuiting with a willingness to } \\
\text { respond to what's needed, often without prior } \\
\text { specialized knowledge }\end{array}$ \\
\hline Hold space & $\begin{array}{l}\text { Holding space focuses the energy of a group. } \\
\text { The artists' presence can hold the space of a } \\
\text { project when the setting is an unconventional } \\
\text { one and especially at the arts, when there are } \\
\text { lots of unknowns }\end{array}$ \\
\hline Connect & $\begin{array}{l}\text { Connecting makes space for coherent and } \\
\text { holistic narratives of where we are now. When } \\
\text { people feel a sense of interconnection, they } \\
\text { transcend the limits of the individual worlds of } \\
\text { 'I' and build a shared story that has meaning } \\
\text { and can inspire the wider community with a } \\
\text { sense of what can happen in between. } \\
\text { Serendipities spring from such connections } \\
\text { between ourselves, the visible and invisible, } \\
\text { the past, present and future, etc }\end{array}$ \\
\hline
\end{tabular}


Table 8.1 (continued)

\begin{tabular}{ll}
\hline Principle & Description \\
\hline Work from commonality & This requires paying attention to what people \\
& have in common; their humanity and common \\
& values. It involves asking good questions and \\
taking care to listen actively. It recognizes and & includes people and makes multiple ways from \\
& them to enter and re-enter a project. Empathy \\
& lies at the heart of working with commonality \\
Collaboration needs humour, open-heartedness \\
and negotiation, all of which are part of its \\
creative dynamic. It is a transformative, \\
complex human process and requires a \\
surrender of some control, but not of rigor \\
and care. It requires an openness to working \\
with others to allow creative journeys to be \\
co-created \\
People's perspectives and sense of capabilities \\
can change. Doors to new possibilities open \\
that might have stayed closed which people \\
jump through into new stories
\end{tabular}

Source Neal 2015, pp. 81-93)

We consider the work of the creative practitioner Yanthe Van Nek within our own case as an example of a PAR-inspired approach, where she interpreted and applied these principles in her own way.

Yanthe is a community artist based in the North of the Netherlands and describes her creative interest in place-based cultural projects as one that resides within chaos - in the space between perfection and destruction. Her philosophy views participatory art as more than just having pleasant conversations. Art, research and the social context must coincide. Therefore an essential part of all of Yanthe's projects is entering and engaging deeply into each other's worlds, building relationships with local people and understanding the dynamics of the place she is working within. This can result in an emergent collective wish or desire for change that then invites her to continue her work with the community on more tangible, visible arts-based activities, having nurtured a degree of trust and consent through engagement with the community. Yanthe views cultural practice as a method to expose structural conflicts, mobilize 
communities and shine light on alternative pathways rather than merely community consultation through art (Pritchard, 2017).

Yanthe addresses the challenge that comes with working within invited spaces through her strategy of becoming ' a voluntary instrument of the community'. To explain this we can use a musical instrument as a metaphor. Yanthe invites the community to 'play' her as if she is an instrument in whichever way they choose. The terms of engagement as to how the community participates in the project are therefore open-ended rather than prescribed. Yanthe is capable of offering a rich repertoire of arts-based skills that they can choose from, but the communityacting as the musician-decides how the instrument is played. Only the community can play Yanthe to a tune of their choosing, external actors (e.g., project administrators) existing outside the co-creative space are not permitted to 'play' Yanthe.

Yanthe's philosophy of co-creation posits the initial engagement process as crucial, immersing herself in both the social and ecological environment of the community. If appropriate and safe to do so, it begins by physically moving into and living within the community space and thereafter conducting an investigation of the desires of community members through the cultivation of meaningful relationships with the residents. This immersive investigation can be guided by community members, moving organically from person to person, picking up information about residents that informed her decisions as to who she should speak to next, including who is marginalized or not spoken about. This provides valuable opportunities to understand local power dynamics - including the dynamics within the community and between the community and the governing authority. The wishes that exist within a community can be explored and can be creatively conceptualized into a collective wish or shared story. This is done through holding the space with individuals for significant periods of time; initiating conversations, listening actively and probing with questions that demonstrate authentic interest. To assist in this investigative process, Yanthe carries around a large book during her conversations, known as 'The Wish Book'-a private book-not shared with any external actor, in which she collects the local residents' inner wishes for the future of the community. She makes it clear that whatever collective desire/wish emerges and can be 
agreed upon, she will utilize her artistic expertise to co-create a cultural expression of their place.

\section{Methodology}

\section{Research Methods}

Empirical evidence for the illustrative case was collected using a mixedmethods approach to qualitative social research. The focus of the data discussed in this chapter was on how Yanthe applied PAR principles, when first engaging with a community in an invited space setting. A combination of six semi-structured and reflective interviews, unstructured walking conversations and a phone interview were conducted with Yanthe over a four month period during Spring 2020. The choice to use observations and interviews as methods of data collection followed from the aim to get a deeper insight into, and understanding of, the practitioner's experiences within the village; these would be much harder to access through more structured data collection methods such as a series of questionnaires (Gillham, 2000; Ritchie \& Lewis, 2003).

While spending time with Yanthe in the village, observations were gathered on how she implemented the first stage of her engagement strategy with the community to nurture the ground for arts-based cocreative practice. The data centred around Yanthe's time setting-up a space for co-creation in a public venue within the centre of the village. The interviews were conducted at the beginning, throughout, and the end of this initial engagement process. The semi-structured interviews and the phone interview were designed to explore Yanthe's strategy of community engagement, with a focus on power dynamics between those who administer the project, her own role and the community. The walking conversations were unstructured in order to encourage Yanthe to freely reflect on her experiences within the village.

The original research plan was to conduct multiple rounds of interviews with the village residents to ensure triangulation and incorporate perceptions of community members on the village developments and cocreative practice. Unfortunately, due to the advent of the COVID-19 
pandemic and subsequent access restrictions implemented by the Dutch government, data collection on-site ceased in May 2020. Instead, the opportunity was taken to deepen the collaboration with Yanthe. Specifically, Yanthe prepared a reflective transcript that summarized her time in the village, and reflected on our conversations and interviews. As well as offering further rich insight, this transcript also helped to guide the analysis. Quotations from this transcript have been included within the results section alongside relevant quotes from interviews to provide context to the analysis. While the analysis of the results remained the responsibility of Davis (lead author) throughout, Yanthe provided valuable contributions to various drafts of the chapter and was active in the editing process to ensure that her philosophy and strategy were accurately described.

\section{Context of the Case}

The chapter employs a single case study approach. This section first provides a description of the illustrative case followed by justification of its suitability for this chapter. The place-based cultural project was part of a wider government-sponsored programme to support the cultural infrastructure and social cohesiveness of the province. The situation in the village was one of additional importance to the provincial authorities, the village having accrued a recent reputation as a place with strong local opposition to their decision to construct a windpark within their surrounding landscape. The windpark was planned as part of a broader national energy transition agenda delivered across the northern Netherlands, and resulted in areas of local resistance in various parts of the province opposing the implementation of energy transition policies. In this village a local action group protested for over seven years in opposition to the windpark. The resistance was triggered by the top-down decision-making process of the provincial government, most notably regarding the large scale of the park, the height of the windmills, and the close distance to the residential area. Community resistance movements like this can be unfairly characterized as NIMBY responses by government actors (Not-In-My-Backyard), but can be alternatively understood 
as rational concern for the future of their place, stemming from a strong local sense of place and serious concerns about local identity (DevineWright \& Clayton, 2010). In this village, the windpark enacted feelings of distrust and volatility towards the provincial government. The protest group acted not just against the provincial deputy in charge, but also against farmers willing to sell their land to the government, therefore enabling the park and further affecting social cohesion within the community.

Illustrative cases are employed to shed light on a particular situation or set of circumstances where social relationships and processes are embedded within them. The overarching purpose of an illustrative case is to address an audience that may not yet be greatly informed about the topic and can offer understandable insights without oversimplification. Therefore, this approach is congruent with our goal of communicating lessons that can be drawn from the creative practitioner's experience to help inform those interested in embarking on an arts-based creative practice journey for the first time.

We regard this as a suitable illustrative case because it is a solid representation of how place-based cultural projects are often externally commissioned in the Netherlands. This project was assigned by a provincial government who opened up the participative space. The same authority supported a series of top-down sustainability and resilience policy decisions that resulted in dis-trust and local opposition. This makes it an interesting and unique case that deserves investigation as to how a creative practitioner can engage with a village from a power relations and trust-building perspective. While we aknowledge that results may not be generalized to other contexts, lessons can nevertheless be derived from this case, for future place-based cultural projects.

\section{Outline of the Engagement Process}

Yanthe's roots lie in the same province as the community village, which was advantageous in respect to having a familiarity and connection to the local context. While she resided in the same general locality, she was not 'local' to the specific community. That is to say that she was 
initially unfamiliar with the community and the dynamics that existed within it upon being invited to work within the space. However, this was also advantageous in a number of ways. It allowed her freedom to enter into the community not bound by existing prejudices or unwritten laws, power dynamics and social norms that consciously or subconsciously determine the actions/behaviours of individuals within the community. Instead, with being a relative outsider, a valuable, anthropological neutrality was present.

As stated, the goal of the initial engagement phase was to nurture the ground for effective arts-based co-creative practice to occur. Yanthe did this by embedding herself within the village and building meaningful relationships with village residents so as to understand and conceptualize the wishes of the community. Although the creative practitioner's strategy was not consciously or explicitly pre-designed based on PAR in a formal sense, she applied methods that closely aligned with the PAR principles that exist within Neal's (2015) 'art of invitation'. She entered the community with an open-ended intention, inductively facilitated the framing of the direction of the project around community desires, and did so by spending time fostering connections that could support transformational change. This helped to democratize the process, resulting in the direction and content of the project resting largely in the hands of the community. Yanthe and the residents engaged co-creatively as explorers, rather than by determining specific outputs beforehand (Reason $\&$ Bradbury, 2008). These explorations took place through living with the community, holding the space in the community for conversations by setting up open-surgeries for residents in the village centre and engaging in local community practices in order to nurture fertile ground for cocreative practice to take place. Unfortunately, due to the onset of the COVID-19 pandemic and subsequent social distancing restrictions, the project was temporarily suspended shortly after this engagement phase, as Yanthe was no longer able to physically hold space within the village due to national COVID social distancing/household regulations. 


\section{Results and Reflections}

What lessons can be learnt from the initial engagement process with a community to nurture ground for co-creative practice? The next subsection reflects on how the creative practitioner dealt with the constraints of working within an invited space. The following sub-sections describe how this constraint was reversed via practicing 'art of invitation' principles and by the practitioner's method of becoming a voluntary instrument of the community. This resulted in the community inviting the creative practitioner to continue the project on their own terms. The last sub-section briefly reflects on time, as a particular constraint that Yanthe could not overcome through the art of invitation.

\section{Power Dynamics and Community Agency Within the Invited Space}

Upon accepting the invitation and entering the village, Yanthe experienced multiple instances of suspicion and cynicism towards the project from a proportion of the village residents. This was predominantly due to opposition within the community to the government's approval for the construction of the windpark, with residents recognizing that the cultural project was administered by the same governmental authority. This resulted in some residents initially rejecting the invitation into the participative space and by consequence rejecting the practitioner. Yanthe articulated:

It was not only the arrival of the windpark, but especially the way in which this change was delivered; it brought an accumulation of unrest within this old village. Feelings of skepticism and a lack of trust from the community were therefore also initially directed towards the project.

This quote highlights how distrust towards external governmental authorities was directed towards the project, not only because of the windpark decision in isolation, but because the community felt they had no real influence or say on the decision-making process itself. By understanding this context, the creative practitioner was able to empathize with 
the initial suspicion and cynicism towards a government administered project to facilitate a cultural expression of their place when they had thus far felt unheard in other participative arenas.

Lessons can be learnt as to why, when entering a community, a creative practitioner or researcher should understand the existing relationship between relevant governmental authorities and the community when the project is funded or sponsored by the state. Such knowledge can inform the community engagement strategy and help to understand resident behaviours that may then be exhibited towards the creative practitioner or researcher upon arrival into the space. If the practitioner is viewed as a representative of the state, this will likely affect the level of trust and time needed to build relationships within the project. It is therefore necessary to fully grasp and empathize with the nature of this distrust by putting into practice the 'art of invitation' principle of working with the community. This requires continuous reflexivity on the practitioner's positionality as a facilitator within the broader social, cultural and political context of the project (see also Horlings et al., 2020).

Having moved into and then begun living within the space, it was necessary for Yanthe to quickly become acquainted with the power dynamics at play and it became necessary for her to impress on the village residents that although her work was funded by an external authority, she was there with the purpose of becoming a voluntary instrument of the community rather than as a commissioned instrument of the state.

Yanthe noted that the governmental authorities were greatly aware of the significant unrest that existed regarding the recent spatial transformations implemented in the village, most notably the windpark construction. She explained that those running the cultural project had expressed concerns to her about the potential for disruptive consequences to occur throughout its duration, due to the current situation. While it could be said that the project was broadly commissioned in the spirit of fostering social cohesiveness and building a cultural infrastructure, the governmental authorities were still concerned with how it would affect the local resistance towards the windpark construction and therefore sought to monitor the co-creative process. This speaks to Gaventa's Hayward-inspired critique of invited spaces whereby the framing and 
limits of what is possible may be at risk of being decided and/or influenced by the external authority in charge of the project rather than by the community. It was therefore important for Yanthe to assert her position as the community engagement specialist to the authorities.

Yanthe made it clear to the government officials overseeing the project that she had been commissioned on the basis that she could implement her methodology of becoming a voluntary instrument of the community, and that it was not possible for her to carry out her methodological process and the subsequent arts-based activities if there was significant external interference. From the beginning of the project, governmental officials had gently probed Yanthe in order to learn about 'what was going on' within the village. This was further demonstrated when one of the public officials suggested they should be present at meetings between the community and Yanthe. Yanthe checked with the residents whether this was appropriate and then communicated that they would not consent to this. This guaranteed that the space being held and facilitated by Yanthe was a private, safe one, creating potential for deeper connections through a demonstration of loyalty to the community, supporting the process of trust-building and community engagement. Participation in practice is 'rarely a seamless process; rather, it constitutes a terrain of contestation, in which relations of power between different actors, each with their own "projects", shape and reshape the boundaries of action' (Cornwall, 2008, p. 276). Yanthe navigated the terrain of contestation and mitigated external interference, securing greater community agency over the project process. She also made it clear to those administering the project from the outset that if residents wanted to use her as an instrument to protest against the arrival of the windmills, that she would facilitate this:

By communicating my chosen position clearly and the position of the participants from the first stages of the project to the funder, it helped in dealing with possible resistance and change of expectations of my client when the project starts naturally evolving in response to the wishes of the community... Due to me outlining clearly the terms of engagement, the local government promised to take the backseat and trust the process. It was very important to emphasise to them the importance of co-ownership and creative freedom of the creators. In my work it is always too easy for me to just push the funders' 
wishes through. After all, in my vocation, I build a relationship of trust [with communities] that is easy to abuse.

The quote illustrates that when a practitioner or researcher aims to apply co-creative arts-based methods it is important to ensure that their preferred community engagement methods are both understood and accepted from the outset by those responsible for initiating an invitational space within a community.

Through building connections with the residents, a shared feeling began to emerge that the residents would rather use the space to create an arts-based symbol of togetherness rather than to further any resistance movements to the windpark construction, disproving concerns from the authorities that the project would be utilized 'disruptively'. Yanthe describes the benefits of a community being given the opportunity to frame the content and project direction:

The community becomes co-creators and co-owners of the project... there are benefits for the funder in relinquishing control within these spaces as the funder gains genuine insights into the wishes, questions, wants and foremost the power and wisdom of the village itself. Instead of seeing a deficit and using culture and 'a creative' to fix it, they can instead trust the process of letting me submerge within a community.

This quote underpins our plea towards governmental authorities, to acknowledge the benefits of relinquishing control over (the framing of) a project to the community.

\section{Building Connections via the Art of Invitation}

Yanthe applied a series of 'art of invitation' principles through her engagement process.

She described the beginning of her process as conducting an investigation by allowing herself to be led by the community: 
I literally let myself be taken away and carried away by the residents, it was they who let me know what they wanted from me as an artist and what any artwork that emerged from this process should bring about. I was a voluntary tool for the inhabitants of village... The residents of the village took me from meeting to meeting. Out on the street and into the houses. I immersed myself in the village and started an intense investigation with all my senses on edge. My days were full of encounters, from the billiard club, the knitting club, boxing, singing, the library, the village school, the village corporation, the party committee, the Youth Box... I spoke with the oldest generation, the parents and the youth. Wherever they took me, I followed every reference.

The essential element of all my projects is to be a part of each other's world. Entering into a relationship, I want to get to know the dynamics of the place where I am going. I found a place to stay at one of the farmers, "wind farmers" as fellow village people call them. I found my workplace at a local car garage, offered to me by one of the village people I had met... From fruitful conversations a widely supported wish emerged. Central themes came to the table such as a feeling from the villagers of having to choose between supporting and opposing the windmills, lamenting the loss of togetherness and a need to reaffirm and perpetuate the feeling of belonging with the help of the existing structures around the rich community life in the village.

Yanthe chose to live and share her evening meals with a local resident, illustrating the art of invitation principle of connecting. This was a microcosm of what Yanthe was trying to achieve across the community as whole. She created a series of connections across the village where a shared story or wish would eventually emerge, building interconnections that transcend the limits of the individual world of 'I' and result in a shared story (Neal, 2015). Yanthe helped this process by ensuring she stayed within the public gaze, 'holding space' in the centre of the village at a local automotive garage. If she was not found behind a table in the garage foyer, she would be seen walking the streets, at people's doors or engaging in local community practices. Always available to actively listen, collaborate and work with the community in their own time. 


\section{The Emergence of Shared Stories and Wishes via the Art of Invitation}

A shared narrative that emerged from individual community desires and was conceptualized into a communal wish, was one of music and festivals. Through her investigation and connections with individual residents, a shared story emerged of the village as how it was once an important part of the blues music scene in the Netherlands. This previous identity of the village had now been largely forgotten and replaced as a village with a reputation for windpark protests. The communal wish was therefore to create an arts-based symbol of the community that paid homage to this musical and festival spirit of the past. Doing so, it was hoped, would foster a renewed sense of community, belonging and togetherness.

Yanthe noted that while there were people passionately for and against the windpark construction, many residents were also broadly neutral on the issue and had more interest in protecting the community from fracturing permanently across this ideological fault line. She reflected:

In all my history, I've never felt such a strong desire for a sense of community from a group of village residents.

While solidarity and resilience within the village was clearly demonstrated through the protests, the deep wishes of the community also highlighted the pressures that the windpark construction decision and resultant protests were placing on the community, exposing potential fragilities. Hence the desire emerged to rekindle a longing for reunification and togetherness and alter the reputation of the village with a symbol to demonstrate that they are not only a village of protest.

Through nurturing connections with the residents and noting their wishes, Yanthe therefore conceptualized a broader shared story that could frame the arts-based co-creative practice-the residents creating their own boundary or structure with which freedom to play can exist (Neal, 2015) while protecting the freedom of participation (Hayward, 1998). In 
this instance the communal wish was to create a new symbol of togetherness for the village through their shared place-based history of music and festival. The process of arts-based co-creative practice began by a local resident expressing this wish at a community gathering through the recital of a poem in the local dialect (see below). 
Summary of a poem in Dutch 'Groninger' dialect

\section{Fire in the village}

My name is Janka Rubingh and

the village has been for 25 years my home

I can say a lot in just a few words

that is my 'Groninger' identity, I guess.

On a good day in the eighties

I was asked for the 'Emergo circle'

It is the village cultural commitee

so you know what it' about......

'Oh village, thou are my land',

a song from 'When blows the wind, it is almost gone'.

the last show in our village of trees,

which can still be heard, and can not be broken. ....

\section{Why are we here today?}

From research it has become cristal clear,

something has been lost here

A wish from long gone past

It is there, but not in front of us

how can we receive this back?

.....

Do we miss one single person,

or an umbrella that binds us together

There is a need for connections

We want to trust each other

and jointly spin one thread together

around everything what goes on here.

And what does happen here then?

Embrace, 40 activities on a row.....

(and then 40 village activities are listed)

Janka Rubingh (translation: Ina Horlings) 
Yanthe's next step was to work with the local choir, to explore the musical aspects of the village that were still alive. This process highlights how Yanthe sees her engagement approach as inductive:

We must work inductively, otherwise we can only be considered "content makers". I do this through creating intense connections. I awake with the village and fall asleep with the village

Yanthe did not arrive as a content maker, imposing her artistic concepts on what she believed would be good for the community. Rather she spent time listening and creating connections, resulting in a shared narrative/wish to emerge that provided the artistic inspiration for a cultural expression of the village to be developed.

\section{Time Constraints}

Due to COVID-19, the next step of co-creating a cultural expression of the village was postponed. Yanthe explained that:

In a post-pandemic world it may be that the residents let me know that my role has been played out. They will have the power to decide whether it is to be continued with or without me

Even amidst the project's suspension, the decision over the direction of the project and Yanthe's future role in it continues to rest in the control of the community.

This was an example of the project being curtailed earlier than expected. Generally Yanthe considers the time limit of projects as openended. She also expressed her frustration over the time constraints of many projects and noted that this is one invitational constraint she cannot mitigate through her methodology:

The funders expect that Friday is my last day and I say goodbye. You raise hopes for the wish, you set things into motion and then due to the constraints 
of the project you have to leave. I give them a platform to share their wishes... so I will not leave until I know they can do it on their own.

In this case, Yanthe stayed in the village by searching and then securing external funding from other sources in order to continue her work with the community after the social distancing measures of COVID-19 were lifted.

Time constraints and juggling pressures are familiar issues with which participatory action researchers also routinely contend. Researchers may not be able to stay beyond an initial agreed project time-scale due to their commitments and demands placed upon them as employees of university institutions. This means that the risk of a 'parachute' effect remains somewhat for social researchers entering communities, resulting in the build-up of relationships and then leaving before the community is ready for the project to end.

In order to enable mutual learning and to learn from the voices and experiences of community members, projects require sufficient time in a community to maintain an open-ended, exploratory engagement with community members. However, there is rarely the political will to provide significant funding for longer term community projects that can facilitate this.

Palmer et al. (2017) advocates the necessity of time, specifically the virtue of a practitioner or researcher 'waiting' within these types of projects, describing this as an important component of communitybased and ethnographic research approaches. This waiting can involve days of drifting and 'nondirective discovery' (Okely, 2012) with discoveries from these open explorations requiring protracted periods of time (Atkinson et al., 2001; Hammersley \& Atkinson, 2007).

\section{Summing Up}

A major theme that emerged from the creative practitioner's engagement strategy was one of relinquishment of control over the direction of the project to the community members. This strategy promoted an authentically inductive approach and coincided with one of the key beneficial 
tenets of PAR — the democratization of the research process. The creative practitioner adjusted the pre-existing paternalistic power dynamic by devolving power bestowed on her by the external authority directly to the community; offering herself voluntarily as an instrument to be used by the community within the invited space. By relinquishing power within the space to the community, this allowed the project objectives to emerge inductively from the residents' wishes. The creative practitioner recognized that being invited into the space by the governmental authority rather than by the community was the first major challenge that needed to be overcome in order to nurture the ground for a tangible cultural expression to take place through arts-based activities.

The artist countered the paternalistic nature of the invitational space by entering into a deep inductive process, spending time living within the village to develop unconditional relationships with the residents. This process reduced suspicion and cynicism of the community members towards the space and instead increased trust towards her motives.

Relinquishing power over the framing and the direction of the project to the community resulted in an emergent wish to use the project to foster togetherness rather than as a vehicle to further protest against the windpark's construction. While still holding strong views on this issue, the project was treated as a reprieve from the continual protests.

\section{Conclusions}

In this chapter we reflected on an illustrative case in the Netherlands to answer the question how a creative practitioner can apply co-creative practice in a community when entering into an invited space, while dealing with situational constraints. We also discussed how best to respond to the wishes of communities on their own terms, rather than to external interests.

Through the conceptual len of an invited space we identified constraints that contributed to the paternalistic manner in which placebased projects are run by governmental authorities, such as the prescribed framing of the project and attempts of external influence over what can be deliberated within the space. 
When embarking on arts-based co-creative practice, it is therefore imperative to recognize the power dynamics often inherent within such spaces. 'Bottom-up' cultural projects ideally facilitate spaces where communities are free to navigate not only consensus-driven themes but also conflicts and existing asymmetrical social relationships:

... where in times of political turmoil, social unrest, chronic housing crises and public sector decimation, culture should be utilised as a way to forge new alliances, social movements and collectives to push against these ills. Culture is not something that should be utilised to maintain the status quo, rather it is an instrument for change (Mould, 2017).

The case discussed in this chapter illustrates how a creative practitioner utilized 'art of invitation' PAR principles to reverse the notion of being invited into the village by an external authority, and instead received consent or an 'invitation' from the community to continue the project on their own terms. The creative practitioner became a 'voluntary instrument of the community', by engaging in an open-ended, inductive process, therefore building trust, connections and collaboration, and encouraging a shared story or communal wish to emerge. As a result, it can be said that the constraints of the invited space were 'flipped on their head' into a community invitation, where the village residents asked her to co-creatively construct a joint arts-based symbol for the village building on the past memories of music festivals that had, in the past, been facilitated by a prominent community member.

The described case provides lessons for those interested in embarking upon an arts-based creative practice journey within a community. These lessons include, first an awareness that entering a village with preconceived assumptions of what is best for the community can create resistance towards connecting and building the relationships needed for an effective project with a lasting legacy. Second, in order to explore the wishes of a community instead of externally pre-described outputs or impacts, the principles of the 'art of invitation' offer an added value to place-based cultural projects. These principles should not be applied as an instrumental tool box but should be used to guide an inductive process. Third, the case showed that through the practitioner becoming 
a voluntary instrument of the community, an authentically inductive approach can be established that can build trust and secure increased community agency that help to mitigate external interference within the participatory space. Fourth, time constraints remain a challenge for government-administered projects.

This chapter argues that when place-based cultural projects take place under invited space conditions, the relationship between researcher/practitioner, the community and the external authority can be viewed as a ménage à trois, with the external authority learning to 'take a back seat' as the project progresses. This is especially relevant for governments in situations where communities might have different ideas or interests about the future of their cultural, physical or environment assets; therefore the projects are not compelled to be framed within these dominant discourses and policy interests. We suggest that practices of 'dissensus' should be welcomed within participatory governance initiatives (Anderson et al., 2016; Kaika, 2017) and that those who work on arts-based creative practice and PAR projects continue to encourage governmental institutions to further democratize participatory spaces. Even when faced with navigating invitational spaces, communities can still then represent and frame their views within co-creative projects, with tangible opportunities to materially influence the future of their place.

Acknowledgements This research received funding from the European Union's Horizon 2020 research and innovation programme under the Marie Sklowdoska-Curie Grant Agreement No. 765389.

\section{References}

Aiyar, Y. (2010). Invited spaces, invited participation: Effects of greater participation on accountability in service delivery. India Review, 9(2), 204-229. Anderson, G. (2017). Participatory action research (PAR) as democratic disruption: New public management and educational research in schools and universities. International Journal of Qualitative Studies in Education, 30(5), 432-449. 
Anderson, M., Hall, D., McEvoy, J., Gilbertz, S., Ward, L., \& Rode, A. (2016). Defending dissensus: Participatory governance and the politics of water measurement in Montana's Yellowstone River Basin. Environmental Politics, 26(5).

Atkinson, P., Coffey, A., Delamont, S., Lofland, J., \& Lofland, L., et al. (2001). Handbook of ethnography: Editorial introduction. In P. Atkinson, A. Coffey, \& S. Delamont (Eds.), Handbook of ethnography (pp. 1-8). Sage. Barca, F. (2009). An agenda for reformed cohesion policy: A place-based approach to meeting European Union challenges and expectations. Independent report prepared at the request of $\mathrm{D}$. Hübner, Commissioner for Regional Policy, Brussels.

Bastida, E., Tseng, T. S., McKeever, C., \& Leonard, J. (2010). Ethics and community-based participatory research: Perspectives from the field. Health Promotion Practice, 11, 16-20.

Battiste, M. (2008). Research ethics for protecting Indigenous knowledge and heritage: Institutional and researcher responsibilities. In N. K. Denzin, Y. S. Lincoln, \& L. Tuhiwai Smith (Eds.), Handbook of critical and Indigenous methodologies (pp. 497-509). Sage.

Carter, K., Banks, S., Armstrong, A., Kindon, S., \& Burkett, I. (2013). Issues of disclosure and intrusion: Ethical challenges for a community researcher. Ethics and Social Welfare, 7, 92-100.

Chevalier, J. M., \& Buckles, D. (2013). Participatory action research: Theory and methods for engaged inquiry. Abingdon-on-Thames.

Cornwall, A. (2002). Making spaces, changing places: Situating participation in development (Working paper series, 170). Brighton: IDS.

Cornwall, A. (2008). Unpacking 'participation': Models, meanings and practices. Community Development Journal, 43(3, 269-283.

Datta, R., Khyang, N. U., Khyang, H. K. P., Kheyang, H. A. P., Khyang, M. C., \& M. C. K., \& Chapola, J. . (2014). Participatory action research and researcher's responsibilities: An experience with an Indigenous community. International Journal of Social Research Methodology, 18(6), 581-599.

de Andrade, M. (2016). Tackling health inequalities through asset-based approaches, co-production and empowerment: Ticking consultation boxes or meaningful engagement with diverse, disadvantaged communities? Journal of Poverty and Social Justice, 24(2), 127-141.

Denzin, N. K., \& Lincoln, Y. S. (Eds.). (2005). The Sage handbook of qualitative research (3rd ed.). Sage. 
Dessein, J., Soini, K., Fairclough, G., \& Horlings, L. (2015). Culture in, for and as sustainable development. Conclusions from the COST ACTION IS1007.

Devine-Wright, P., \& Clayton, S. (2010). Introduction to the special issue: Place, identity and environmental behaviour. Journal of Environmental Psychology, 30, 267-270.

Duxbury, N., \& Jeannotte, E. (2007). Culture as a key dimension of sustainability: Exploring concepts, themes, and models (Working Paper 1). Creative City network of Canada; Centre of Expertise on Culture and Communities: Vancouver.

Encounters A. https://civicroleartsinquiry.gulbenkian.org.uk/resources/encoun ters.

Encounters B. https://civicroleartsinquiry.gulbenkian.org.uk/resources/encoun ters.

Facer, K., \& Enright, B. (2016). Creating living knowledge: The connected communities programme, community-university partnerships and the participatory turn in the production of knowledge. Arts and Humanities Research Council. https://connectedcommunities.org/index.php/creating-liv ing-knowledge-report/.

Gaventa, J. (2006). Finding the spaces for change: A power analysis. IDS Bulletin, 37(6), 23-33.

Gaventa, J. (2009). Power pack: Understanding power for social change. http://www.powercube.net/wpcontent/uploads/2010/01/PowerPack_web_ version.pdf.

Gillham, B. (2000). Case study research methods. Continuum.

Gordon-Fairleigh, J. (2015). Reclaiming the commons. In L. Neal (Ed.), Playing for time: Making art as if the world mattered. Oberon Books Ltd.

Grenni, S., Horlings, L. G., \& Soini, K. (2020). Linking spatial planning and place branding strategies through cultural narratives in places. European Planning Studies, 28(7), 1355-1374.

Hacker, K. (2013). Community-based participatory research. Sage.

Hammersley M., \& Atkinson P. (2007). Ethnography: Principles in practice. Routledge.

Hawkes, J. (2001). The fourth pillar of sustainability: Culture's essential role in public planning. Common Ground Publishing Pty Ltd.

Hayward, C. R. (1998). De-facing power. Polity, 31(1), 1-22.

Heron, J., \& Reason, P. (2006). The practice of co-operative inquiry: Research "with" rather than "on" people. In P. Reason \& H. Bradbury (Eds.), Handbook of action research (pp. 144-154). Sage. 
Hopkins, R. (2015). Relocalisation and the transition movement. In L. Neal (Ed.), Playing for time: Making art as if the world mattered. Oberon Books Ltd.

Horlings, L. (2017). The role of artists and researchers in sustainable placeshaping. In S. Asikainen, C. Brites, K. Plebańczyk, L. R. Mijatović \& K. Soini (Eds.), Culture in sustainability: Towards a transdisciplinary approach (Vol. 139, pp. 130-143). University of Jyväskylä.

Horlings, L. G., Nieto-Romero, M., \& Pisters, S. (2020). "Operationalising transformative sustainability science through place-based research: The role of researchers. Sustainability Science, 15, 467-484.

Ingold, T. (2000). The perception of the environment: Essays on livelihood, dwellong and skill. Routledge.

Kaika, M. (2017). 'Don't call me resilient again!': The new urban agenda as immunology ... or ... what happens when communities refuse to be vaccinated with 'smart cities' and indicators. Environment and Urbanization, 29, 89-102.

Kelly, K., \& van der Riet, M. (2001). Participatory research in community settings: Processes, methods and challenges. In M. Seedat, N. Duncan, \& S. Lazarus (Eds.), Community psychology: Theory, method and practice. South African and other perspectives (pp. 159-188). Oxford University Press.

Kesby, M. (2005). Re-theorising empowerment-through-participation as a performance in space: Beyond tyranny to transformation. Signs: Journal of Women in Culture and Society, 30, 2037-2065.

Khan, R. (2015). Art in community: The provisional citizen. Palgrave McMillan.

Leavy, P. (2018). Introduction to arts-based research. In P. Leavy (Ed.), Handbook of arts-based research (pp. 3-21). Guilford Press.

MacKinnon, D. (2002). Rural governance and local involvement: Assessing state-Community relations in the Scottish highlands. Journal of Rural Studies, 18(3), 307-324.

Metz, A., Boaz, A., \& Robert, G. (2019). Co-creative approaches to knowledge production: What next for bridging the research to practice gap? Evidence \& Policy, 1(7).

Mouffe, C. (2013). Agonistics: Thinking the world politically. Verso.

Mould, O. (2017). Why culture competitions and 'artwashing' drive urban inequality. Open Democracy. https://www.opendemocracy.net/en/opende mocracyuk/why-culture-competitions-and-artwashing-drive-urban-inequa lity/.

Neal, L. (2015). Playing for time: Making art as if the world mattered. Oberon Books Ltd. 
Noorani, T., Blencowe, C., \& Brigstocke, J. (2013). Problems of participation: Reflections on democracy, authority, and the struggle for common life. ARN Press.

Nunn, C. (2020). The participatory arts-based research project as an exceptional sphere of belonging. Qualitative Research.

Oakley, P., \& Marsden, D. (1985). Approaches to participation in rural development. ILO.

Okely, J. (2012). Anthropological practice: Fieldwork and the ethnographic method. Berg.

Palmer, J., Burton, L., \& Walsh, A. (2020). Emerging spheres of engagement: The role of trust and care in community-university research. Qualitative Research, 20, 749-766.

Palmer, J., Pocock, C., \& Burton, L. (2017). Waiting, power and time in ethnographic and community based research. Qualitative Research, 18(4), 416-432.

Pritchard, S. (2017). Artwashing: Social capital \& anti-gentrification activism. Colouring in Culture. https://colouringinculture.org/uncategorized/artwas hingsocialcapitalantigentrification.

Reason, P., \& Bradbury, H. (2008). The Sage handbook of action research (2nd ed.). Sage.

Ritchie, J., \& Lewis, J. (2003). Qualitative research practice: A guide for social science students and researchers. Sage

Shortridge, J. R. (2005). Regional image and sense of place in Kansas. Kansas History: A Journal of the Central Plains, 28(Autumn), 202-219.

Svensson, E. (2012). Achieving sustainable lifestyles? socio-cultural dispositions, collective action and material culture as problems and possibilities. Local Environment, 17(3), 269-286.

Thomas-Hughes, H (2018). Ethical 'mess' in co-produced research: reflections from a U.K.-based case study. International Journal of Social Research Methodology, 21(2), 231-242.

Throsby, D. (2008). Culture in sustainable development: Insights for the future implementation of art. Convention on the protection and promotion of the diversity of cultural expressions. Unesco.

United Cities and Local Governments (UCLG). (2008). Agenda 21 for culture. http://www.agenda21culture.net/sites/default/files/files/documents/ multi/ag21_en.pdf.

van Westen, R., \& van Dijk, D. (2015). European Union: RICHES_Good practices and methods for co-creation. https://resources.riches-project.eu/wp- 
content/uploads/2015/12/RICHES-D4-2-Good-practices-and-methodsfor-co-creation_public.pdf.

Williams, R. (1980). Problems in materialism and culture. Verso.

Wilson, E., Kenny, A., \& Dickson-Swift, V. (2017). Ethical challenges in community-based participatory research: A scoping review. Qualitative Health Research, 28(2), 189.

Yamini, A. (2010). Invited spaces, invited participation: Effects of greater participation on accountability in service delivery. India Review, 9(2), 204-229.

Yanthe Van Nek. (2020). https://www.yanthe.com/.

Open Access This chapter is licensed under the terms of the Creative Commons Attribution 4.0 International License (http://creativecommons.org/ licenses/by/4.0/), which permits use, sharing, adaptation, distribution and reproduction in any medium or format, as long as you give appropriate credit to the original author(s) and the source, provide a link to the Creative Commons license and indicate if changes were made.

The images or other third party material in this chapter are included in the chapter's Creative Commons license, unless indicated otherwise in a credit line to the material. If material is not included in the chapter's Creative Commons license and your intended use is not permitted by statutory regulation or exceeds the permitted use, you will need to obtain permission directly from the copyright holder. 